\title{
DETERIORAÇÃO DE SEMENTES DE CROTALARIA JUNCEA E SUAS CONSEQÜÊNCIAS EM LABORATÓRIO E CAMPO ( $\left.{ }^{1}\right)$
}

\author{
JOCELY ANDREUCCETTI MAEDA $\left(^{2}\right)$, \\ ANTONIO LUIZ DE BARROS SALGADO $(3,4)$ \\ e ANTONIO AUGUSTO DO LAGO $(2,4)$
}

\begin{abstract}
RESUMO
Sementes de Crotalaria juncea L. com conteúdos de umidade de 6,3 e $11,1 \%$, foram armazenadas por 84 meses em condiçōes ambientes e às temperaturas controladas de 20 e $30^{\circ} \mathrm{C}$, e testadas periodicamente no laboratório quanto a germinação e vigor (índice de velocidade de germinação) e no campo quanto a emergência, altura da planta, produção de massa seca (massa vegetal na maturaçăo) e de sementes. Até aos 30 meses, não se observaram diferenças significativas de germinação entre as sementes nas diversas condiçôes, apresentando todas porcentagens acima de 90. Dos 30 meses em diante, as sementes armazenadas nas condições de maior umidade e temperatura exibiram maior velocidade de deterioração, notadamente as mantidas com $11,1 \%$ de umidade a $30^{\circ} \mathrm{C}$, que mostraram germinação e vigor praticamente nulos a partir dos 66 meses. As sementes com 6,3\% de umidade mantiveram germinação acima de $90 \%$ até aos 84 meses, independente da temperatura. Do quarto ano de plantio em diante, as sementes armazenadas com $11,1 \%$ de umidade a $30^{\circ} \mathrm{C}$ se destacaram negativamente das demais quanto a "stand", produção de massa seca e de sementes. Das condiçōes estudadas, as mais ade-
\end{abstract}

(1) Trabalho apresentado na 38a Reuniâo Anual da SBPC, Curitiba (PR), 9-16 de julho de 1986. Recebìdo para publicaçāo em 22 de abril de 1986.

(2) Seçäo de Sementes, Instituto Agronômico (IAC), Caixa Postal 28, 13001 Campinas (SP).

(3) Seção de Plantas Fibrosas, IAC.

(4) Com bolsa de suplementaçāo do CNPq. 
quadas para a preservaçāo da longevidade das sementes foram a secagem a $6,3 \%$ de umidade e manutenção a 20 ou $30^{\circ} \mathrm{C}$, tendo as sementes assim armazenadas apresentado, ao final dos sete anos, satisfatorios níveis de germinação e vigor e bom comportamento no campo.

Termos de indexaçāo: Crotalaria juncea, sementes, deterioração, germinação, vigor, produçãa.

\section{INTRODUÇÃO}

A planta de Crotalaria juncea apresenta auto-incompatibilidade, isto é, o pólen produzido por uma flor não consegue fecundar a mesma flor nem outra flor da mesma planta, mas somente flores de outra planta. Dessa maneira, a polinização depende da presença de determinados insetos para que haja produçāo de sementes. Em conseqüência, a produçăo de sementes dessa leguminosa torna-se bastante irregular, sendo variável de ano para ano (SALGADO et alii, 1984).

Essa irregularidade obriga os produtores a manter estoques de sementes, às vezes até dois anos agrícolas, com risco de perdas, uma vez que as condiçōes mais adequadas para sua conservação não são satisfatoriamente conhecidas. O problema é ainda mais delicado em instituições de pesquisa e bancos de germoplasma (ITO, 1972; JAMES, 1972; CAMARGO et alii, 1974), onde existe a necessidade de preservação, por diversos anos, de certa quantidade de sementes com alto valor cultural, para uso dos melhoristas e estudiosos dessa leguminosa.

Uma vez que os principais fatores que afetam a longevidade das sementes são o seu conteúdo de umidade e a temperatura de armazenamento (HARRINGTON, 1972), o presente experimento teve por objetivo estudar a viabilidade, o vigor e o valor de plantio de sementes de Crotalaria juncea mantidas com diferentes conteúdos de umidade e a diferentes temperaturas, e sob condiçōes não controladas de armazém, por 84 meses.

\section{MATERIAL E MÉTODOS}

As sementes de Crotalaria juncea L. utilizadas foram do cultivar Comum , produzidas no Centro Experimental de Campinas, no ano agrícola 1973/74. Após batidas e limpas, uma porção uniforme de $12,5 \mathrm{~kg}$ de sementes foi dividida em cinco subporçōes de $2,5 \mathrm{~kg}$ cada uma. Duas dessas subporções, após secagem a $35^{\circ} \mathrm{C}$ em secador com circulação forçada de ar até umidade de $6,3 \%$, foram colocadas dentro de frascos de vidro hermeticamente fechados e armazenadas a 20 e $30^{\circ} \mathrm{C}$. As outras três subporçōes permaneceram com a umidade inicial $(11,1 \%)$, sendo duas delas armazenadas também em frascos de vidro às 
temperaturas de 20 e $30^{\circ} \mathrm{C}$. A quinta subporção foi embalada em saco de pano e mantida em condiçōes comuns de armazém, sujeita, portanto, às variaçōes de temperatura e umidade relativa da região de Campinas.

A cada trimestre, até 12 meses e, daí em diante, a cada semestre até o total de 84 meses, as sementes foram testadas em laboratório quanto a conteúdo de umidade, germinação e vigor.

Nas épocas normais de plantio, que se iniciaram no ano agrícola 1974/75 e prolongaram-se por sete anos consecutivos até o ano agrícola 1980/81, realizou-se a semeadura no campo, e durante o desenvolvimento da cultura efetuaram-se mediçōes de "stand", altura das plantas, produção de massa seca (massa vegetal na maturação) e produção de sementes.

O conteúdo de umidade foi determinado com duas repetiçōes de aproximadamente $20 \mathrm{~g}$ cada uma, em estufa a $105^{\circ} \mathrm{C}$, sem circulação forçada de ar, por 24 horas, calculando-se os resultados com base no peso úmido (BRASIL, 1980).

O teste de germinação foi realizado com quatro repetições de 50 sementes cada uma, em substrato rolo de papel, a $20-30^{\circ} \mathrm{C}$, com a primeira contagem aos dois dias e a última, aos sete dias.

O teste de vigor foi efetuado em conjunto com o de germinação, constando do índice de velocidade de germinação. Do segundo dia em diante até o sétimo dia, as plântulas foram examinadas diariamente à mesma hora, retirando-se e contando-se as consideradas normais e que tinham atingido um comprimento total (parte aérea + radícula) de, no minimo, $5,0 \mathrm{~cm}$. Para obtenção do indice de velocidade de germinação, multiplicou-se o número de plântulas normais retiradas a cada dia pelo inverso do número de dias após o início do teste, e somaram-se os valores obtidos (VAUGHAN, 1971; POPINIGIS, 1977).

O ensaio de campo, conduzido no Centro Experimental de Campinas, teve delineamento inteiramente casualizado, com cinco tratamentos e quatro repetições. Cada parcela foi formada por cinco linhas de $5 \mathrm{~m}$ cada uma, separadas entre si por $0,40 \mathrm{~m}$. A densidade de semeadura foi de 35 sementes por metro linear. Para a tomada dos dados, aproveitaram-se somente as três linhas centrais.

O "stand" final foi determinado na época normal de colheita, contando-se o número de plantas nas três linhas e calculando-se o número de plantas por metro linear.

A altura foi avaliada também na época de colheita, medindo-se a altura, em centimetro, de dez plantas tomadas ao acaso no interior das três linhas centrais; com esses dados, calculou-se a média de altura das plantas da parcela.

Efetuou-se a colheita com as plantas em plena maturação, ceifando-se, bem rente ao solo, os caules. Estes foram pesados e seus ponteiros, batidos sobre um encerado para extraçāo e pesagem das sementes. Com os dados obtidos, calculou-se o peso de massa seca e de sementes, em quilogramas por hectare. 


\section{RESULTADOS E DISCUSSÃO}

Os conteúdos de umidade das sementes permaneceram relativamente estáveis durante todo o periodo de armazenamento, tendo flutuado ao redor dos valores iniciais, com exceção daquelas mantidas no ambiente. Estas assumiram conteúdos de umidade ligeiramente mais baixos que o inicial $(11,1 \%)$, tendo variado em torno de $10,8 \%$, que parece ter sido a umidade de sementes de Crotalaria juncea, em equilibrio com a umidade relativa ambiente da região de Campinas.

As porcentagens de germinação e comparação de médias nos diversos períodos de armazenamento encontram-se no quadro 1. Verifica-se que, até os 30 meses, não ocorreram diferenças significativas de germinação entre as sementes mantidas nas diversas condiçōes, apresentando todas porcentagens acima de 90. A partir dos 30 meses, as sementes armazenadas nas condições de maior umidade e temperatura exibiram maior velocidade de deterioração, notadamente as mantidas com $11,1 \%$ de umidade a $30^{\circ} \mathrm{C}$, cuja germinação se tornou muito baixa dos 66 meses em diante.

As sementes com o nivel baixo de umidade de 6,3\% mantiveram germinação acima de $90 \%$ até os 84 meses, independente da temperatura. Por outro lado, o efeito da temperatura foi marcante nas sementes armazenadas com umidade de $11,1 \%$. Assim, enquanto as sementes com $11,1 \%$ de umidade e armazenadas a $20^{\circ} \mathrm{C}$ mostraram o bom indice de germinação de $75,6 \%$ aos 84 meses, aquelas mantidas a $30^{\circ} \mathrm{C}$ apresentaram índice semelhante só até aos 42 meses. Esse efeito conjunto de umidade da semente e temperatura de armazenamento, bem estudado e explicado por HARRINGTON (1972), mostra que sementes em geral podem ser armazenadas a temperaturas relativamente altas, desde que convenientemente secas.

As sementes armazenadas em condições ambientes mantiveram germinação de $70 \%$ ou acima até os 54 meses; dai em diante, a deterioração foi relativamente rápida, com germinação de apenas $21,9 \%$ aos 84 meses.

Pelos dados de vigor do quadro 2, observa-se que as sementes mantidas com o nivel mais baixo de umidade $(6,3 \%)$ exibiram, numa aparente contradição, menores índices de vigor até os 24 meses. Como até aquele período não tinha havido diferenças significativas de deterioração entre os diversos tratamentos, isso pode ter ocorrido por estar o teor de umidade de $6,3 \%$ mais distante do ponto crítico para início de germinação das sementes, refletindo em menor velocidade do processo, quando comparadas com aquelas que apresentavam inicialmente teor de umidade de $11,1 \%$. Testes de velocidade de germinação ou de emergência são particularmente sensiveis a pequenas variações nas condiçōes de germinação, principalmente com relação a umidade e temperatura. 
QUADRO 1. Porcentagens médias de germinaçăo de sementes de Crotalaria juncea mantidas em diferentes condiçöes, e após diversos perfodos de armazenamento ( $\left.{ }^{1}\right)$

\begin{tabular}{|c|c|c|c|c|c|c|c|c|}
\hline \multirow{2}{*}{ Meses } & \multicolumn{5}{|c|}{ Condiçöes de armazenamento } & \multirow{2}{*}{ F. $\left({ }^{2}\right)$} & \multirow{2}{*}{$\underset{(\%)}{C . V .}$} & \multirow{2}{*}{ D.M.S. } \\
\hline & $6,3 \%$ U $/ 20^{\circ} \mathrm{C}$ & $6,3 \% \mathrm{U} / 30^{\circ} \mathrm{C}$ & $11,1 \% \cup r 20^{\circ} \mathrm{C}$ & $11,1 \% \mathrm{U} / 30^{\circ} \mathrm{C}$ & Ambiente & & & \\
\hline 03 & 97,0 & 99,8 & 96,6 & 95,5 & 95,1 & 1,40 n.s. & 6,0 & - \\
\hline 06 & 93,8 & 94,4 & 94,2 & 96,7 & 95,1 & 1,03 n.s. & 3,8 & - \\
\hline 09 & 96,6 & 95,5 & 95,7 & 93,2 & 98,2 & 1,73n.s. & 5,2 & - \\
\hline 12 & 97,1 & 99,8 & 96,2 & 93,3 & 95,3 & 2,50 n.s. & 5,7 & - \\
\hline 18 & 97,4 & 96,9 & 96,2 & 95,0 & 96,7 & 0,41 n.s. & 5,3 & - \\
\hline 24 & $97 ; 4$ & 98,8 & 97,6 & 92,1 & 99,2 & 2,41 n.s. & 6,9 & - \\
\hline 30 & 96,0 & 95,5 & 95,7 & 95,2 & 91,2 & 1,49n.s. & 5,1 & - \\
\hline 36 & $97,0 \mathrm{a}\left({ }^{3}\right)$ & $93,0 \mathrm{ab}$ & $92,4 \mathrm{ab}$ & $82,5 b$ & $88,2 \mathrm{ab}$ & $4,43^{*}$ & 7,1 & 11,3 \\
\hline 42 & $99,1 \mathrm{a}$ & $99,1 \mathrm{a}$ & $95,7 \mathrm{a}$ & $77,7 \mathrm{c}$ & $87,5 b$ & $45,15 * *$ & 3,9 & 6,5 \\
\hline 48 & $95,3 a$ & $98,2 a$ & $94,2 \mathrm{a}$ & $57,6 c$ & $71,1 b$ & $65,24^{* *}$ & 5,2 & 7,7 \\
\hline 54 & $98,8 a$ & $94,9 a b$ & $93,2 b$ & $35,0 d$ & $70,0 \mathrm{c}$ & $143,67 * *$ & 4,9 & 7,0 \\
\hline 60 & $96,7 a$ & $96,7 \mathrm{a}$ & $94,8 \mathrm{a}$ & $24,6 c$ & $69,0 b$ & $228,56^{* *}$ & 4,5 & 6,3 \\
\hline 66 & $97,6 a b$ & $98,5 a$ & $90,5 b$ & $8,0 d$ & $41,0 c$ & $145,87 * *$ & 8,3 & 10,6 \\
\hline 72 & $98,5 a$ & $98,4 \mathrm{a}$ & $91,0 \mathrm{a}$ & $3,4 c$ & $38,5 b$ & $174,58^{* *}$ & 8,4 & 10,5 \\
\hline 78 & $99,5 a$ & $97,6 a$ & $79,2 \mathrm{~b}$ & $0,5 \mathrm{~d}$ & $24,6 \mathrm{c}$ & $387,53^{* *}$ & 6,7 & 7,8 \\
\hline 84 & $94,0 \mathrm{a}$ & $97,8 \mathrm{a}$ & $75,6 \mathrm{~b}$ & $0,9 \mathrm{~d}$ & $21,9 \mathrm{c}$ & $386,86 * *$ & 6,6 & 7,2 \\
\hline
\end{tabular}

(1) As porcentagens de germinação inicial, antes e depois da secagem, foram de $93,5(5,5 \%$ de sementes duras) e de 97,0 (2,0\% de sementes duras) respectivamente.

(2) Os valores de F., C.V.e D.M.S., assim como a comparaçăo de médias, säo correspondentes aos dados transformados em arco seno $\sqrt{\% \text {. }}$

$\left({ }^{3}\right)$ Médias, no mesmo perfodo de armazenamento, seguidas pela mesma letra, não diferem estatisticamente entre si pelo teste de Tukey a $5 \%$.

QUADRO 2. Valores médios de vigor (fndice de velocidade de germinaçăo) de sementes de Cratalaria juncea mantidas em diferentes condiçöes, e após diversos perfodos de armazenamento ( ${ }^{t}$ )

\begin{tabular}{|c|c|c|c|c|c|c|c|c|}
\hline \multirow{2}{*}{ Meses } & \multicolumn{5}{|c|}{ Condiçōes de armazenamento } & \multirow{2}{*}{ F. $\left({ }^{2}\right)$} & \multirow{2}{*}{$\underset{(\%)}{C . V .}$} & \multirow{2}{*}{ D.M.S. } \\
\hline & $6,3 \% \mathrm{U} / 20^{\circ} \mathrm{C}$ & $6,3 \% \mathrm{U} / 30^{\circ} \mathrm{C}$ & $11,1 \% \mathrm{U} / 20^{\circ} \mathrm{C}$ & $11,1 \% \mathrm{U} / 30^{\circ} \mathrm{C}$ & Ambiente & & & \\
\hline 03 & $17,4 c\left(^{2}\right)$ & $19,4 b$ & $21,8 a$ & $20,7 \mathrm{ab}$ & $21,2 \mathrm{ab}$ & $19,65^{* *}$ & 4,0 & 1,8 \\
\hline 06 & $17,8 b$ & $16,6 b$ & $21,4 a$ & $22,1 \mathrm{a}$ & $21,1 \mathrm{a}$ & $14,69 * *$ & 6,4 & 2,8 \\
\hline 09 & $22,0 \mathrm{bc}$ & $21,4 c$ & $23,7 \mathrm{a}$ & $23,1 \mathrm{ab}$ & $24,2 \mathrm{a}$ & $13,39 * *$ & 2,7 & 1,3 \\
\hline 12 & $19,8 \mathrm{~b}$ & $21,1 \mathrm{ab}$ & $22,1 \mathbf{a}$ & $21,5 \mathrm{ab}$ & $22,5 a$ & $5,71 * *$ & 4,2 & 1,9 \\
\hline 18 & $22,1 \mathrm{a}$ & $21,2 b c$ & $22,3 a$ & $20,6 c$ & $21,6 \mathrm{a}$ & $13,43 * *$ & 1,7 & 0,8 \\
\hline 24 & $19,6 b$ & $19,3 b$ & $22,1 \mathrm{a}$ & $18,6 b$ & $18,4 b$ & $10,73 * *$ & 4,6 & 2,0 \\
\hline 30 & $18,2 a$ & $16,8 \mathrm{a}$ & $18,5 \mathrm{a}$ & $14,1 \mathrm{~b}$ & $14,3 b$ & $16,84 * *$ & 6,3 & 2,2 \\
\hline 36 & $20,5 a$ & $18,3 \mathrm{ab}$ & $19,8 \mathrm{a}$ & $13,8 \mathrm{c}$ & $16,8 b$ & $25,35 * *$ & 6,0 & 2,3 \\
\hline 42 & $19,0 \mathrm{a}$ & $18,6 \mathrm{a}$ & $18,6 \mathrm{a}$ & $11,2 \mathrm{c}$ & $14,0 \mathrm{~b}$ & $98,62 * *$ & 4,4 & 1,5 \\
\hline 48 & $20,1 a$ & $19,8 \mathrm{a}$ & $20,0 \mathrm{a}$ & $7,8 \mathrm{c}$ & $12,9 b$ & $169,95^{* *}$ & 5,3 & 1,9 \\
\hline 54 & $20,7 a$ & $19,7 \mathrm{a}$ & $19,3 a$ & $4,1 c$ & $11,7 b$ & $432,89 * *$ & 4,5 & 1,5 \\
\hline 60 & $17,9 a$ & $16,9 \mathrm{ab}$ & $16,0 b$ & $2,4 d$ & $10,3 c$ & $313,94^{* *}$ & 5,7 & 1,6 \\
\hline 66 & $16,0 a$ & $16,6 a$ & $13,3 b$ & $0,2 d$ & $4,8 \mathrm{c}$ & $594,81^{* *}$ & 5,9 & 1,3 \\
\hline 72 & $16,1 \mathbf{a}$ & $16,0 \mathrm{a}$ & $13,1 b$ & $0,0 \mathrm{~d}$ & $4,7 c$ & $914,52^{* *}$ & 4,8 & 1,0 \\
\hline 78 & $16,5 a$ & $16,1 \mathrm{a}$ & $12,4 b$ & $0,1 d$ & $3,9 c$ & $882,76^{* *}$ & 5,1 & 1,1 \\
\hline 84 & $15,1 a$ & $14,0 \mathrm{a}$ & $11,5 b$ & $0,1 d$ & $2,1 c$ & $372,71 * *$ & 8,4 & 1,6 \\
\hline
\end{tabular}

(1) Os valores de vigor inicial, antes e depois da secagem, foram de 19,4 e 18,6 respectivamente.

(2) MEdias, no mesmo perfodo de armazenamento, seguidas pela mesma letra, não diferem estatisticamente cntre si pelo teste de Tukey a $5 \%$. 
Aos 30 meses e dai em diante, as diferenças em velocidade de germinação fizeram-se sentir, sobrepondo-se à de umidade, tendo as sementes com $6,3 \%$ de umidade e mantidas a 20 ou $30^{\circ} \mathrm{C}$ apresentado maiores índices de vigor, principalmente dos 60 meses em diante, quando comparadas ao armazenamento com teores de umidade mais elevados.

As sementes armazenadas em condiçōes ambientes ou com $11,1 \%$ de umidade a $30^{\circ} \mathrm{C}$ decresceram mais rapidamente em vigor do que as outras, exibindo indices praticamente nulos a partir dos 66 meses.

Seguindo os modelos de deterioração de sementes estudados e desenvolvidos, notadamente por DELOUCHE \& BASKIN (1973), o vigor das sementes de crotalária decresceu de forma mais acentuada que a germinação. Dessa maneira, enquanto as diferenças em germinação se fizeram sentir somente a partir dos 36 meses, as devidas essencialmente a vigor ocorreram já a partir dos trinta meses.

As diferenças em "stand" acompanharam, em linhas gerais, as verificadas em germinação e vigor durante o periodo de armazenamento (Quadro 3). Até o $3^{\circ}$ ano de plantio, não ocorreram diferenças estatísticas de "stand" entre os diversos tratamentos. No $4^{\circ}$ plantio e dai em diante, as sementes armazenadas com $11,1 \%$ de umidade a $30^{\circ} \mathrm{C}$ mostraram "stand" estatisticamente inferior aos demais, atingindo valor extremamente baixo no $6^{\circ}$ e nulo no $7^{\circ}$. Por essa razão, esse tratamento não fez parte dos estudos posteriores de altura, produçáo de massa seca e de sementes, no $7^{\circ}$ ano.

Considerando-se 20-25 plantas por metro linear como um bom "stand" para Crotalaria juncea, verifica-se que somente as sementes armazenadas com $6,3 \%$ de umidade a 20 ou $30^{\circ} \mathrm{C}$ mantiveram esse nível por todo o período de armazenamento, independente das diferenças de microambiente em que a cultura se desenvolveu, verificadas entre os sete anos de plantio.

QUADRO 3. Valores medios de "stand" final (número por metro linear) de plantas de Crokalaria juncea provenientes de sementes mantidas em diferentes condiçöes, $e$ semeadas por sete anos agrícolas consecutivos

\begin{tabular}{|c|c|c|c|c|c|c|c|c|}
\hline \multirow{2}{*}{$\begin{array}{l}\text { Anos de } \\
\text { plantio }\end{array}$} & \multicolumn{5}{|c|}{ Condiçōes de armazenamento } & \multirow{2}{*}{ F. } & \multirow{2}{*}{$\begin{array}{l}\text { C.V. } \\
(\%)\end{array}$} & \multirow{2}{*}{ D.M.S. } \\
\hline & $6,3 \% \mathrm{U} / 20^{\circ} \mathrm{C}$ & $6,3 \% \mathrm{U} / 30^{\circ} \mathrm{C}$ & $11,1 \% \mathrm{U} / 20^{\circ} \mathrm{C}$ & $11,1 \% \mathrm{U} / 30^{\circ} \mathrm{C}$ & Ambiente & & & \\
\hline $1^{\circ}(74 / 75)$ & 27,6 & 29,4 & 29,1 & 28,2 & 28,0 & 0,89 n.s. & 5,8 & - \\
\hline $2^{\circ}(75 / 76)$ & 29,0 & 28,5 & 28,3 & 28,0 & 27,8 & 1,12 n.s. & 3,2 & - \\
\hline $3^{\circ}(76 / 77)$ & 28,1 & 27,8 & 27,8 & 27,8 & 27,7 & 0,20 n.s. & 2,5 & - \\
\hline $4^{\circ}(77 / 78)$ & $27,2 \mathrm{a}\left({ }^{1}\right)$ & $27,3 \mathrm{a}$ & $27,0 \mathrm{a}$ & $25,6 \mathrm{~b}$ & $26,7 \mathrm{a}$ & $9,50^{* *}$ & 1,7 & 1,0 \\
\hline $5^{\circ}(78 / 79)$ & $21,5 \mathrm{a}$ & $22,9 a$ & $21,0 \mathrm{a}$ & $3,9 b$ & $18,3 a$ & $30,77^{* *}$ & 16,1 & 6,1 \\
\hline $6^{\circ}(79 / 80)$ & $25,5 a$ & $22,7 a b$ & $18,0 \mathrm{bc}$ & $0,8 d$ & $16,4 \mathrm{c}$ & $45,35 * *$ & 17,0 & 6,2 \\
\hline $7^{\circ}(80 / 81)$ & $26,5 a$ & $25,5 \mathrm{a}$ & $15,0 \mathrm{~b}$ & $0,0 d$ & $13,5 \mathrm{c}$ & $1932,33^{* *}$ & 3,0 & 1,1 \\
\hline
\end{tabular}

(1) MEdias, no mesmo ano agrfcola, seguidas pela mesma letra, năo diferem estatisticamente entre si pelo teste de Tukey a $5 \%$ 
O quadro 4 revela que apenas as sementes mantidas com $11,1 \%$ de umidade a $30^{\circ} \mathrm{C}$ destacaram-se negativamente das demais quanto a altura de planta e, mesmo assim, somente no $5^{\circ}$ e $6^{\circ}$ ano de plantio. Essa observação vem confirmar que sementes mais deterioradas e menos vigorosas germinam e emergem mais lentamente e, com freqüência, produzem plantas mais baixas, tanto no estádio jovem como no adulto. Cumpre ressaltar, no entanto, que tal fato nem sempre é verificado. GILL (1969) e SITTISROUNG (1970), trabalhando com milho e arroz, respectivamente, notaram que, embora nos estádios iniciais de desenvolvimento houvesse diferenças de altura entre plantas provenientes de sementes com diferentes níveis de deterioração e vigor, ao atingir o estádio adulto, as mesmas plantas apresentaram alturas estatisticamente iguais.

Os dados de massa seca e a comparação de médias encontram-se no quadro 5. Diferenças estatísticas só se observaram no quarto ano e dai em diante, sendo as sementes mantidas com $11,1 \%$ de umidade a $30^{\circ} \mathrm{C}$ as que apresentaram produções de massa seca inferiores às demais, que foram iguais entre si.

QUADRO 4. Alturas medias de plantas de Crotalaria juncea provenientes de sementes mantidas em diferentes condiçōes, e semeadas por sete anos agrícolas consecutivos

\begin{tabular}{|c|c|c|c|c|c|c|c|c|}
\hline \multirow{2}{*}{$\begin{array}{l}\text { Anos de } \\
\text { plantio }\end{array}$} & \multicolumn{5}{|c|}{ Condiçōes de armazenamento } & \multirow{2}{*}{ F. } & \multirow{2}{*}{ C.V. } & \multirow{2}{*}{ D.M.S. } \\
\hline & $6,3 \% \mathrm{U} / 20^{\circ} \mathrm{C}$ & $6,3 \% \mathrm{U} / 30^{\circ} \mathrm{C}$ & $11,1 \% \mathrm{U} / 20^{\circ} \mathrm{C}$ & $11,1 \% \mathrm{U} / 30^{\circ} \mathrm{C}$ & Ambiente & & & \\
\hline & & & $-\mathrm{cm}-$ & & & & $\%$ & \\
\hline $19(74 / 75)$ & 320,0 & 310,0 & 320,0 & 330,0 & 330,0 & 3,00 n.s. & 3,0 & - \\
\hline $2^{\circ}(75 / 76)$ & 330,0 & 320,0 & 320,0 & 330,0 & 320,0 & $3,00 \mathrm{n} . \mathrm{s}$. & 2,0 & - \\
\hline $39(76 / 77)$ & 335,0 & 340,0 & 332,5 & 330,0 & 330,0 & 0,41 n.s. & 3,9 & - \\
\hline $4^{\circ}(77 / 78)$ & 315,0 & 300,0 & 297,5 & 292,5 & 297,5 & 1,06n.s. & 5,5 & - \\
\hline $59(78 / 79)$ & $372,5 \mathrm{ab}\left({ }^{1}\right)$ & $372,5 a b$ & $387,5 a$ & $365,0 \mathrm{~b}$ & $382,5 \mathrm{ab}$ & $4,00^{*}$ & 2,4 & 19,5 \\
\hline $6=(79 / 80)$ & $298,8 \mathrm{a}$ & $303,8 a$ & $296,2 a$ & $232,5 b$ & $292,5 \mathrm{a}$ & $10,02^{* *}$ & 6,5 & 40,7 \\
\hline $7^{\circ}(80 / 81)$ & 283,8 & 270,0 & 272,5 & - & 268,8 & 1,35n.s. & 4,3 & - \\
\hline
\end{tabular}

(1) Medias, no mesmo ano agricola, seguidas pela mesma letra, nåo diferem estatisticamente entre si pelo teste de Tukey a $5 \%$.

QUADRO 5. Produçōes médias de massa seca de plantas de Crotalaria juncea provenientes de sementes mantidas em diferentes condiçöes, e semeadas por sete anos agricolas consecutivos

\begin{tabular}{|c|c|c|c|c|c|c|c|c|}
\hline \multirow{2}{*}{$\begin{array}{l}\text { Anos de } \\
\text { plantio }\end{array}$} & \multicolumn{5}{|c|}{ Condiçöes de armazenamento } & \multirow{2}{*}{ F. } & \multirow{2}{*}{ c.V. } & \multirow{2}{*}{ D.M.S. } \\
\hline & $6,3 \% \mathrm{U} / 20^{\circ} \mathrm{C}$ & $6,3 \% \mathrm{U} / 30^{\circ} \mathrm{C}$ & $11,1 \% \mathrm{U} / 20^{\circ} \mathrm{C}$ & $11,1 \% \mathrm{U} / 30^{\circ} \mathrm{C}$ & Ambiente & & & \\
\hline & & & $-\mathbf{k g} / \mathbf{h a}$ & & & & $\%$ & \\
\hline $19(74 / 75)$ & $25.325,0$ & $25.925,0$ & $27.125,0$ & $25.025,0$ & $25.450,0$ & $0,48 \mathrm{n} . \mathrm{s}$ & 9,2 & - \\
\hline $2^{\circ}(75 / 76)$ & $13.540,0\left(^{1}\right)$ & $13.570,0$ & $14.540,0$ & $13.420,0$ & $13.330,0$ & 0,41 n.s. & 11,2 & - \\
\hline $3^{\circ}(76 / 77)$ & $14.892,5$ & $12.970,0$ & $14.740,0$ & $15.627,5$ & $13.127,5$ & $1,41 \mathrm{~ns}$ & 13,8 & - \\
\hline $4^{\circ}(77 / 78)$ & $20.572,5 \mathrm{a}\left({ }^{2}\right)$ & $18.437,5 \mathrm{ab}$ & $16.565,0 \mathrm{ab}$ & $13.542,5 b$ & $18.177,5 \mathrm{ab}$ & $4,30^{*}$ & 14,5 & $5.529,3$ \\
\hline $59(78 / 79)$ & $33.525,0 \mathrm{a}$ & $33.905,0 \mathrm{a}$ & $31.355,0 \mathrm{a}$ & $18.021,2 b$ & $28.647,5 \mathrm{a}$ & $11,81 * *$ & 13,1 & $8.308,3$ \\
\hline $60(79 / 80)$ & $19.500,0 \mathrm{a}$ & $19.625,0 a$ & $16.875,0 \mathrm{a}$ & $3.125,0 \mathrm{~b}$ & $17.250,0 \mathrm{a}$ & $97,67^{* *}$ & 9,2 & $3.054,5$ \\
\hline $70(80 / 81)$ & $20.675,0$ & $20.225,0$ & $18.625,0$ & - & $19.500,0$ & $1,73 \mathrm{n}$ s. & 6,9 & - \\
\hline
\end{tabular}

(1) As baixas produçbes de massa seca em $75 / 76$ foram devidas à ocorrencia de murcha nas plantas.

(2) MEdias, no mesmo ano agricola, seguidas pela mesma letra, năo diferem estatisticamente entre si pelo teste de Tukey a $5 \%$. 
Embora no $6^{\circ}$ e $7^{\circ}$ plantio as sementes armazenadas no ambiente exibissem "stands" inferiores aos melhores (Quadro 3), o mesmo não ocorreu quanto à produção de massa seca. Como essa redução em "stand" não foi muito drástica, é provável que as plantas delas advindas, tendo maior espaço e competindo menos entre si, apresentassem maior desenvolvimento vegetativo, o que compensou aquela deficiência.

Os dados de produção de sementes expostos no quadro 6 revelam que, tal como ocorreu para "stand" e massa seca, diferenças estatísticas só foram observadas do quarto ano em diante, tendo as sementes armazenadas com $11,1 \%$ de umidade a $30^{\circ} \mathrm{C}$ se destacado negativamente das demais. No $7^{\circ}$ ano de plantio, as armazenadas no ambiente ou com $11,1 \%$ de umidade a $20^{\circ} \mathrm{C}$ apresentaram "stands" mais baixos (Quadro 3), que não se refletiram em um decréscimo na produção de massa seca, dado o maior desenvolvimento individual das plantas (Quadro 5). Esse fato também não teve reflexo em uma maior produção de sementes, tendo os tratamentos citados (ambiente ou com $11,1 \%$ de umidade a $20^{\circ} \mathrm{C}$ ) sido estatisticamente inferiores àqueles em que as sementes foram mantidas com $6,3 \%$ de umidade a 20 ou $30^{\circ} \mathrm{C}$. Estes últimos ainda apresentavam, no $7^{\circ}$ ano de plantio, as boas produções de 857,5 e $868,8 \mathrm{~kg} / \mathrm{ha}$ de sementes respectivamente.

Os resultados do presente trabalho demonstram a boa longevidade das sementes de Crotalaria juncea, pois mesmo aquelas ao nivel normal de umidade de $10,8 \%$ e armazenadas no ambiente, mantiveram, por quatro anos, bons índices de germinação e vigor e satisfatório comportamento no campo.

Das condiçōes estudadas, as mais adequadas para a preservaçāo da longevidade das sementes foram a secagem a $6,3 \%$ de umidade e manutenção a 20 ou $30^{\circ} \mathrm{C}$, tendo as sementes assim armazenadas apresentado, ao final dos sete anos, niveis satisfatórios de germinaçăo e vigor, e exibido, no campo, adequados "stands", com boas produçōes de massa seca e de sementes.

QUADRO 6. Produçōes médias de sementes por planta de Crotalaria juncea provenientes de sementes mantidas em diversas condiçöes, e semcadas por sete anos agrícolas consecutivos

\begin{tabular}{|c|c|c|c|c|c|c|c|c|}
\hline \multirow{2}{*}{$\begin{array}{l}\text { Anos de } \\
\text { plantio }\end{array}$} & \multicolumn{5}{|c|}{ Condiçöes de armazenamento } & \multirow{2}{*}{ F. } & \multirow{2}{*}{ C.V. } & \multirow{2}{*}{ D.M.S. } \\
\hline & $6,3 \%$ U $/ 20^{\circ} \mathrm{C}$ & $6,3 \% \mathrm{U} / 30^{\circ} \mathrm{C}$ & $11,1 \% \mathrm{U} / 20^{\circ} \mathrm{C}$ & $11,1 \% \mathrm{U} / 30^{\circ} \mathrm{C}$ & Ambiente & & & \\
\hline & & & $\mathrm{kg} / \mathrm{ha}$ & & & & $\%$ & \\
\hline $10(74 / 75)$ & $1.412,5$ & $1.262,5$ & 1.345 & $1.632,5$ & $1.467,5$ & 2,67 n.s. & 8,5 & - \\
\hline$(75 / 76)$ & $420,0(1)$ & & & 380,0 & & 1,20 n.s. & 17,3 & - \\
\hline $3^{\circ}(76 / 77)$ & $1.007,5$ & 937,5 & 933,7 & 920,0 & 895,0 & $0,45 \mathrm{n} . \mathrm{s}$. & 12,8 & \\
\hline $4^{\circ}(77 / 78)$ & $1.313,8 \mathrm{ab}\left({ }^{2}\right)$ & $1.110,0 \mathrm{ab}$ & $1.108,8 \mathrm{ab}$ & $958,8 b$ & $1.328,8 \mathrm{a}$ & $3,58^{*}$ & 14,2 & 360,7 \\
\hline $5=(78 / 79)$ & $712,5 \mathrm{a}$ & $662,5 a$ & $600,0 a$ & $311,2 \mathrm{~b}$ & $677,5 \mathrm{a}$ & $12,60^{* *}$ & 15,4 & 200,1 \\
\hline $6 \div(79 / 80)$ & $867,5 \mathrm{ab}$ & $967,5 \mathrm{a}$ & $930,0 \mathrm{ab}$ & $167,5 \mathrm{c}$ & $680,0 \mathrm{~b}$ & $30,47 * *$ & 16,5 & 260,8 \\
\hline $7 \times(80 / 81)$ & $857,5 \mathrm{a}$ & $868,8 a$ & $485,0 \mathrm{~b}$ & - & $450,0 \mathrm{~b}$ & $175,96 * *$ & 5,2 & 72,5 \\
\hline
\end{tabular}

(1) As baixas produçð̌es de sementes em $75 / 76$ foram devidas a ocorrencia de murcha nas plantas.

(2) Medias, no mesmo ano agrícola, seguidas pela mesma letra, nåo diferem estatisticamente entre sị pelo teste de Tukey a $5 \%$. 


\title{
SUMMARY
}

\author{
DETERIORATION OF CROTALARIA JUNCEA SEEDS AND ITS \\ CONSEQUENCES UNDER LABORATORY AND FIELD CONDITIONS
}

Crotalaria juncea L. seeds with $6.3 \%$ and $11.1 \%$ moisture contents were stored for 84 months under room temperature and controlled conditions (at $20^{\circ} \mathrm{C}$ and $30^{\circ} \mathrm{C}$ ). The seeds were tested periodically, in the laboratory for germination and vigor (germination speed index) and in the field, for emergence, plant height, green matter production (at time of maturation) and grain yield. No significant differences among the seeds were observed up to 30 months of storage, under the several conditions, all presenting above $90 \%$ seed germination. After 30 months of storage, the seeds under conditions of high moisture and temperature exhibited faster deterioration: those maintained with $11.1 \%$ moisture at $30^{\circ} \mathrm{C}$, showed practically no germination and vigor after 66 months. Seeds with $6.3 \%$ moisture content maintained the percentage of germination above 90 up to 84 months, at both temperatures, $20^{\circ} \mathrm{C}$ or $30^{\circ} \mathrm{C}$. From the fourth planting year on, the seeds stored with $11.1 \%$ moisture at $30^{\circ} \mathrm{C}$ showed large differences as to stand, green matter production and grain yield. Of the conditions studied, the most adequate for seed longevity preservation was the one that kept $6.3 \%$ seed moisture content at either $20^{\circ} \mathrm{C}$ or $30^{\circ} \mathrm{C}$. After seven years the seeds so stored presented satisfactory levels of germination and vigor, and good performance in the field.

Index terms: Crotalaria juncea L., deterioration, seeds, germination, vigor, production.

\section{REFERÊNCIAS BIBLIOGRÁFICAS}

BRASIL. Ministério da Agricultura. Escritório de Produção Vegetal. Equipe Técnica de Sementes e Mudas. Regras para análise de sementes. Brasilia, 1980. 188p.

CAMARGO, C.P; GREGG, B.R. \& LINGERFELT, C.W. Banco nacional de germoplasma. Brasilia, Ministério da Agricultura, AGIPLAN, 1974. 40p.

DELOUCHE, J.C. \& BASKIN, C.C. Accelerated aging techniques for predicting the relative storability of seed lots. Seed Science and Technology, 1:427-452, 1973.

GILL, N.S. Deterioration of corn (Zea mays L.) seed during storage. State College, Mississippi State University, 1969. 199p. Dissertaçāo (Doutorado)

HARRINGTON, J.F. Problems of seed storage. In: HEYDECKER, W., ed. Seed ecology. University Park and London, The Pennsylvania State University Press, 1972. p.251-263.

ITO, H. Organization of the national Seed Storage Laboratory for Genetic Resources in Japan. In: ROBERTS, E.H., ed. Viability of seeds. Syracuse, Syracuse University Press, 1972. p.405-416.

JAMES, E. Organization of the United States Seed Storage Laboratory. In: ROBERTS, E.H., ed. Viability of seeds. Syracuse, Syracuse University Press, 1972. p.397-404.

POPINIGIS, F. Fisiologia da semente. Brasília, AGIPLAN, 1977. 289p. 
SALGADO, A.L.B.; AZZINI, A.; PIMENTEL, J.M. \& POTASCHEFF JÚNIOR, J. Instruções para a cultura da crotalária júncea visando à produção de fibras. Campinas, Instituto Agronômico, 1984. 27p. (Boletim, 198)

SITTISROUNG, P. Deterioration of rice (Oryza sativa $\mathrm{L}$.) seed in storage and its influence on field performance. State College, Mississippi State University, 1970. 91p. Dissertação (Doutorado)

VAUGHAN, C.E. Practical seed tests and their uses. In: PROCEEDINGS SHORT COURSE FOR SEEDSMEN. State College, Seed Technology Laboratory, 1971. p.69-74. 